Cahiers $d u$ MONDE RUSSE

\section{Cahiers du monde russe}

Russie - Empire russe - Union soviétique et États indépendants

$49 / 4 \mid 2008$

Destins individuels et terreur. Jeunesse dans la société post-stalinienne

\title{
Bianca Pietrow-Ennker, éd., Kultur in der Geschichte Russlands
}

\section{Gábor T. Rittersporn}

\section{(2) OpenEdition}

1 Journals

Édition électronique

URL : https://journals.openedition.org/monderusse/7028

DOI : $10.4000 /$ monderusse. 7028

ISSN : $1777-5388$

Éditeur

Éditions de l'EHESS

\section{Édition imprimée}

Date de publication : 28 décembre 2008

Pagination : 854-857

ISBN : 978-2-7132-2197-2

ISSN : $1252-6576$

Référence électronique

Gábor T. Rittersporn, «Bianca Pietrow-Ennker, éd., Kultur in der Geschichte Russlands », Cahiers du monde russe [En ligne], 49/4 | 2008, mis en ligne le 24 décembre 2009, consulté le 03 septembre 2022. URL : http://journals.openedition.org/monderusse/7028; DOI : https://doi.org/10.4000/ monderusse.7028

Ce document a été généré automatiquement le 3 septembre 2022.

Tous droits réservés 


\title{
Bianca Pietrow-Ennker, éd., Kultur in der Geschichte Russlands
}

\author{
Gábor T. Rittersporn
}

\section{RÉFÉRENCE}

Bianca PIETROW-ENNKER, éd., Kultur in der Geschichte Russlands. Räume, Medien, Identitäten, Lebenswelten. Göttingen : Vandenhoeck \& Ruprecht 2007, 392 p.

1 Il y a six ans, la Fondation Humboldt réunissait ses anciens boursiers français pour un colloque sur la Kulturwissenschaft. Prudemment, le titre du programme mentionnait aussi les sciences humaines. En fait, c'est avant tout de ces dernières que traitèrent la plupart des participants. Ici et là on pouvait entendre, dans les conversations de couloir, que la Kulturwissen-schaft n'était finalement qu'une manifestation de plus du souci prétendument allemand d'inventer de nouvelles disciplines dont on n'a nul besoin. Le terme - que l'on peut traduire approximativement par «science de la culture »couvrait un terrain extrêmement large, mal défini et au vrai indéfinissable. Certes, arguait-on, il était de plus en plus difficile de fixer les limites des disciplines académiques, qu'il s'agisse d'histoire ou de physique. Raison de plus pour ne pas complexifier les choses en tentant de délimiter un domaine de recherche pas moins flou que les autres.

2 Mais, demandèrent les collègues allemands, pourquoi se compliquer la vie en tentant de classer l'inclassable? Pourquoi refuser d'assumer l'instabilité des frontières des immenses champs de nos connaissances potentielles, pourquoi ne pas passer à son aise d'un terrain à l'autre, pourquoi se laisser piéger par les règles de tel ou tel exercice académique au lieu de puiser librement dans la panoplie de toutes les disciplines possibles? Certes, répondaient les détracteurs, mais n'est-ce pas ce qu'on appelle interdisciplinarité - pratique courante en sociologie, en histoire, en économie comme dans bien d'autres spécialités ? Bien - rétorquèrent enseignants et étudiants des instituts de Kulturwissenschaft de Francfort-sur-l'Oder à Paderborn, de Berlin à Tübingen et de 
Bonn à Coblence..., néanmoins, au lieu de ne se pencher que sur le passé, le social ou les différentes façons de faire du profit, ne faudrait-il pas mieux parler d'abord d'une chose aussi vaste que le vécu de l'homme? Réponse exaspérante car, une fois de plus, ils faisaient appel à un terme, Lebenswelt, qui n'a pas vraiment cours de ce côté-ci du Rhin, surtout dans les études sur la Russie. Forgée par un poète, Heinrich Heine, l'expression a été conceptualisée grâce à Simmel, Dilthey, Husserl, Troeltsch, Schütz et Habermas.

3 La Kulturwissenschaft couvre un champ incomparablement plus large que les cultural studies qui sont pratiquées avant tout dans les pays anglo-saxons. Elle fonctionne à partir d'une conception bien plus étendue de la culture, allant bien plus loin que les cultural studies qui limitent l'horizon de l'homme dans une perspective essentiellement politique. Cependant, les deux démarches s'apparentent par leur postulat qui consiste à appréhender les manifestations de la culture comme des textes et des symboles que l'on peut décoder.

4 Cela valait la peine de s'attarder sur la Kulturwissenschaft, car la rédactrice du volume, Bianca Pietrow-Ennker, se réclame de cette école. Loin de dissimuler l'ampleur quelque peu déconcertante de la discipline, elle dit clairement que l'on a affaire à tout ce qui relève de l'expérience de l'homme, à tout ce qui façonne ses représentations du monde et de soi-même et enfin à tout ce qui en résulte quand il s'affronte à son univers. Vaste projet, même si on ne l'axe que sur la Russie. Il serait déraisonnable d'exiger qu'un recueil d'études l'embrasse dans toutes ses dimensions. Mais les textes choisis par Pietrow-Ennker révèlent que, même si le terme de «science de la culture » peut laisser rêveur, les thèmes de recherche et les démarches qu'il autorise ont toutes les chances de porter des fruits.

5 Une partie est consacrée à la perception et à l'interprétation de l'espace ainsi qu'aux lieux de mémoire que celles-ci peuvent instituer. Guido Hausmann examine les rôles qu'un lieu bien défini joue dans l'imaginaire ainsi que les différentes lectures que le chercheur peut en donner. Il déchiffre les légendes liées à la fondation du monastère de Tolg, qui manifestent l'apparition d'une nouvelle sensibilité pour la nature au XVII siècle et d'une géographie symbolique où la Volga devient un fleuve associé à la vision du monde orthodoxe et aux vertus chrétiennes. Oliver Reisner décrit l'appropriation intellectuelle de la colonisation du Caucase tant par les Russes et les indigènes que par les poètes romantiques du XIX ${ }^{\mathrm{e}}$ siècle et d'autres intellectuels, jusqu'aux savants du siècle suivant. Il met en évidence contradictions et interférences dans la lecture d'un espace, qui suscitent des conflits jusqu'à nos jours. Tom Jürgens se penche sur l'appropriation des étendues de la Sibérie à travers sa représentation dans les musées, qui débouche sur la soviétisation des manières de visualiser un vaste territoire.

6 La deuxième section de l'ouvrage explore divers médias en se fondant sur le postulat de Marshall McLuhan quant à leur fonction comme incarnation de messages. Jurij Murašov dévoile les liens entre livre imprimé et lutte contre l'hérésie judaïsante au $\mathrm{XVI}^{\mathrm{e}}$ siècle. Riccardo Nicolosi fait le tour de la Kunstkamera de Pierre le Grand. Il la voit comme un microcosme que l'on peut replacer dans la perspective de l'occidentalisation de la Russie et de l'agencement de son symbole, Saint-Pétersbourg. Ingrid Schierle investigue le langage. Elle étudie l'évolution du terme "otečestvo » au XvIII siècle, qui allait désigner aussi bien la patrie que le lien émotionnel entre le souverain et ses sujets dans la culture officielle, tout en pouvant véhiculer aussi des valeurs républicaines.

7 La troisième partie traite de la construction des identités. Lutz Häfner la saisit à travers l'évolution du rôle du duel qui redéfinissait les marqueurs de l'honneur et de la bonne 
société. L'analyse d'un portrait de famille et d'un récit par Elisabeth Cheauré, Antonia Napp et Elisabeth Vogel fait ressortir la complexité de la relation entre patrie, famille et féminité au XIX ${ }^{e}$ siècle. Susi K. Frank montre comment les théories raciales appliquées à la Sibérie deviennent porteuses d'une identité impériale. Rainer Lindner parcourt un long siècle de l'histoire de la ville de Iekaterinoslav, que Catherine II avait fondée comme le symbole de l'idée impériale et que des entrepreneurs ont transformée en exemple type du boom économique et de la modernisation de la société à la fin du XIX ${ }^{\mathrm{e}}$ siècle.

La section suivante replace le vécu humain dans la perspective des changements sociaux. Julia Obertreis retrace les origines de l'appartement communautaire dans les années 1920, lorsque des sous-locataires reprennent à leur compte le discours officiel sur la lutte des classes. Carmen Scheide montre le lien entre l'influence du discours officiel sur la femme et la rationalisation, par celle-ci, de son expérience dans les années 1930. Jörg Baberowski décrit le conflit entre un pouvoir soucieux d'imposer sa conception du monde liée au progrès et un Orient soviétique qui s'y refuse, même sous la pression de la terreur. Eva Maeder observe le quotidien des vieux-croyants en Transbaïkalie : certaines traditions datant de l'ancien régime ont survécu depuis la naissance du régime bolchevique jusqu'à nos jours, tandis que nombre de pratiques se sont adaptées aux conditions soviétiques.

Enfin, la dernière partie confronte les récits du pouvoir au pouvoir des récits. Birgit Menzel dépiste rêves, fantasmes et désirs obscurs de fans soviétiques et post-soviétiques de science-fiction. Des motifs liés à l'anti-utopie, au racisme et à la mission impériale de la Russie y apparaissaient déjà sous l'ancien régime. Rosalinde Sartorti élucide l'impact de l'image médiatique de Vladimir Putin sur le public aussi bien que sur la manière dont l'homme politique se présente devant son audience. Jana Bürgers invite à lire dans un parc à thèmes originellement soviétique l'imagerie du Cosaque en Ukraine, qui deviendra figure emblématique dans le discours officiel après l'effondrement de l'URSS.

Baberowski expose bien l'idée qui sous-tend le volume. En suivant Cassirer et Dilthey, il explique que notre univers n'existe pour nous que dans la mesure où nous le saisissons en fonction de codes culturels. Il fut un temps où les recherches sur le monde soviétique étaient captives de l'argument du procureur Andrej Vyšinskij qui proclamait que tout était politique. Paraphrasant la déclaration de ce personnage douteux, nos auteurs et la Kulturwissenschaft proposent que tout soit culture. Ils ont sans doute raison de suggérer que tout ce que l'on vit et fait, ainsi que tout ce que l'on peut devenir, est inséparable d'un contexte culturel donné.

11 Mais il est permis de se demander si la sphère du politique n'occupe pas une place à peine moins importante pour certains de nos auteurs que celle que lui accordent les cultural studies. Après tout, ils ont la malchance de travailler sur le pays du procureur Vyšinskij et non sur des peuples heureux qui n'ont pas d'histoire. Aussi, les collègues qui appliquent des méthodes liées à la sémiologie ou qui explorent les mentalités et lieux de mémoire n'ont pas entièrement tort de penser qu'à l'instar de Monsieur Jourdain qui faisait de la prose sans le savoir, ils pratiquent certaines des démarches de la Kulturwissenschaft.

Devons-nous craindre d'être les témoins innocents de l'émergence d'une nouvelle orthodoxie, somme toute un peu moins nouvelle qu'elle ne l'apparaît au premier abord ? Peu importe. Nos travaux ne peuvent que gagner beaucoup à s'inspirer des leçons du recueil dirigé par Pietrow-Ennker. 